\title{
An Experimental and Theoretical Study on the Ionization Energies of Polyynes $\left(\mathrm{H}-(\mathrm{C} \equiv \mathrm{C})_{n}-\mathrm{H} ; \mathrm{n}=1-9\right)$
}

\author{
Ralf I. Kaiser \\ Department of Chemistry, University of Hawaii at Manoa, Honolulu, HI 96822, USA
}

Bian Jian Sun, Hong Mao Lin, Agnes H. H. Chang Department of Chemistry, National Dong Hwa University, Hualien 974, Taiwan

\begin{abstract}
Alexander M. Mebel
Department of Chemistry and Biochemistry, Florida International University, Miami, FL 33199
\end{abstract}

\section{Oleg Kostko, Musahid Ahmed}

Chemical Sciences Division, Lawrence Berkeley National Laboratory, Berkeley, CA 94720

\section{Astrophysical Journal}

(submitted May 2010) 


\begin{abstract}
We present a combined experimental and theoretical work on the ionization energies of polyacetylene - organic molecules considered as important building blocks to form polycyclic aromatic hydrocarbons (PAHs) in the proto planetary nebulae such as of CRL 618. This set of astrophysical data can be utilized with significant confidence in future astrochemical models of photon-dominated regions and also of the proto planetary nebulae CRL 618. We recommend ionization energies of polyacetylenes from diacetylene up to heptaacetylene with an experimental accuracy of $\pm 0.05 \mathrm{eV}: 10.03 \mathrm{eV}$ (diacetylene), $9.45 \mathrm{eV}$ (triacetylene), $9.08 \mathrm{eV}$ (tetraacetylene), $8.75 \mathrm{eV}$ (pentaacetylene), $8.65 \mathrm{eV}$ (hexaacetylene), and $8.50 \mathrm{eV}$ (heptaacetylene); further, ionization energies and with an accuracy of $\pm 0.1 \mathrm{eV}: 8.32 \mathrm{eV}$ (octaacetylene) and $8.24 \mathrm{eV}$ (nonaacetylene) were computed. Implications of these energies to the redox chemistry involved in the multiply charged metal-ion mediated chemistry of hydrocarbon-rich atmospheres of planets and their moons such as Titan are also discussed.
\end{abstract}




\section{INTRODUCTION}

Polyacetylenes (polyynes) are linear molecules of the generic formula $\mathrm{H}(\mathrm{C} \equiv \mathrm{C})_{\mathrm{n}} \mathrm{H}$ and hold

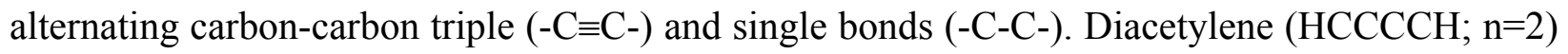
and triacetylene $(\mathrm{HCCCCCCH} ; n=3)$ present the two most prominent members of this class of molecules. Due to their linearity and closed shell structure, they have ${ }^{1} \Sigma_{\mathrm{g}}{ }^{+}$electronic ground states and belong to the $\mathrm{D}_{\infty \mathrm{h}}$ point group. In extraterrestrial environments, photochemical models predict that these highly unsaturated polyacetylenes contribute significantly to the astrochemical evolution of the interstellar medium (Cernicharo 2004; Woods et al. 2003), since they present crucial building blocks to form polycyclic aromatic hydrocarbons (PAHs) (Pardo \& Cernicharo 2007). Polyacetylenes are often posited as the missing link between small gas phase molecules, among them acetylene $\left(\mathrm{C}_{2} \mathrm{H}_{2}\right)$, carbon monoxide $(\mathrm{CO})$, and hydrogen cyanide $(\mathrm{HCN})$, and carbonaceous grain particles formed in the outflow of carbon -rich stars (Cordiner \& Millar 2009; Duley et al. 2005). Most noticeable, diacetylene and triacetylene have been monitored spectroscopically toward the proto planetary nebulae CRL 618 (Cernicharo et al. 2001) formed by a star that passed through the red giant phase. The central star emits a strong ultraviolet (UV) and vacuum ultraviolet (VUV) radiation field, which in turn can ionize and photo dissociate organic molecules (Boechat-Roberty et al. 2009). The photon-driven chemistry could eventually lead to the formation of aromatic molecules such as benzene (Woods et al. 2002). However, all chemical models simulating the astrochemical evolution of distinct interstellar environments depend on accurate input parameters such as reaction rates, products, photodissociation cross sections, and ionization energies. Whereas the formation and growth of polyacetylenes in cold, extraterrestrial environments involves barrier-less, bimolecular reactions ethynyl $\left(\mathrm{C}_{2} \mathrm{H} ; \mathrm{X}^{2} \Sigma^{+}\right)$and 1,3-butadiynyl radicals $\left(\mathrm{C}_{4} \mathrm{H} ; \mathrm{X}^{2} \Sigma^{+}\right)$(reactions (1) and (2), respectively) (Gu et al. 2009), only little attention has been given to derive ionization energies of complex polyacetylenes. Utilizing photoioniza- 
tion molecular beam mass spectrometry of hydrocarbon flames, Hansen et al. (2008) and Li et al. (2009) recommended ionization energies of 10.17 and $10.15 \mathrm{eV}$ (diacetylene; $\mathrm{C}_{4} \mathrm{H}_{2}$ ), 9.50 and $9.48 \mathrm{eV}$ (triacetylene; $\mathrm{C}_{6} \mathrm{H}_{2}$ ), 9.08 and $9.06 \mathrm{eV}$ (tetraacetylene; $\mathrm{C}_{8} \mathrm{H}_{2}$ ), and 8.82 and $8.77 \mathrm{eV}$ (pentaacetylene; $\mathrm{C}_{10} \mathrm{H}_{2}$ ). These energies were reported to be accurate within $0.05 \mathrm{eV}$. Li et al. also suggested an ionization energy of $8.56 \pm 0.05 \mathrm{eV}$ for hexaacetylene $\left(\mathrm{C}_{12} \mathrm{H}_{2}\right)$. The lack of ionization energies for the higher members can be attributed to their thermal instability and hence difficulties to form these molecules either by a direct synthesis or in situ in combustion flames.

$$
\begin{array}{ll}
\mathrm{C}_{2} \mathrm{H}\left(\mathrm{X}^{2} \Sigma^{+}\right)+\mathrm{H}(\mathrm{C} \equiv \mathrm{C})_{\mathrm{n}} \mathrm{H}\left(\mathrm{X}^{1} \Sigma_{\mathrm{g}}{ }^{+}\right) & \rightarrow \mathrm{H}(\mathrm{C} \equiv \mathrm{C})_{\mathrm{n}+1} \mathrm{H}\left(\mathrm{X}^{1} \Sigma_{\mathrm{g}}{ }^{+}\right)+\mathrm{H} \\
\mathrm{C}_{4} \mathrm{H}\left(\mathrm{X}^{2} \Sigma^{+}\right)+\mathrm{H}(\mathrm{C} \equiv \mathrm{C})_{\mathrm{n}} \mathrm{H}\left(\mathrm{X}^{1} \Sigma_{\mathrm{g}}{ }^{+}\right) & \rightarrow \mathrm{H}(\mathrm{C} \equiv \mathrm{C})_{\mathrm{n}+2} \mathrm{H}\left(\mathrm{X}^{1} \Sigma_{\mathrm{g}}{ }^{+}\right)+\mathrm{H}
\end{array}
$$

Since these ionization energies are vital to constrain chemical models of distinct interstellar environments such as those of pre planetary nebulae and also of hydrocarbon rich atmospheres of planets and their moons like Titan, we have conducted a combined experimental and theoretical study on the ionization energies of polyynes up to nonaacetylene $\left(\mathrm{C}_{18} \mathrm{H}_{2}\right)$. Here, the adiabatic ionization energy (IE) presents a measurable quantity of the energy required to remove an electron from a molecule in its rotational, vibrational, and electronic ground state hence forming a cation in its lowest electronic, vibrational, and rotational level. The adiabatic ionization energy presents one of the most relevant thermochemical measurements: ionization energies can not only be utilized to determine the nature of the structural isomers, i.e. of hydrocarbon radicals, but they can also be combined with thermochemical cycles to obtain enthalpies of formation of hydrocarbon radicals. Here, we extract the ionization energies by synthesizing polyynes on line and in situ in an ablation source within a supersonic molecular beam and photoionizing these species by vacuum ultraviolet (VUV) light from the Advanced Light Source at various photon energies up to $10.5 \mathrm{eV}$. This in situ preparation of highly labile organic transient molecules has 
been applied recently to measure ionization energies of two important interstellar hydrocarbon radicals: the linear and cyclic $\mathrm{C}_{3} \mathrm{H}$ isomers. Their ionization energies were determined to be 9.15 $\pm 0.05 \mathrm{eV}$ and $9.76 \pm 0.05 \mathrm{eV}$, respectively (Kaiser et al. 2007). Supported by electronic structure calculations, the recorded photoionization efficiency (PIE) curves of the polyyne ions are then compared with theoretically obtained adiabatic ionization energies in this work.

\section{EXPERIMENTAL}

The photoionization studies were carried out at the Chemical Dynamics Beamline of the Advanced Light Source at Lawrence Berkeley National Laboratory (Heimann et al. 1997). We utilized two complementary approaches to synthesize the polyynes on line and in situ within a laser ablation source (Nicolas et al. 2006; Kaiser et al. 2007). In two separate experiments, 1-2 $\mathrm{mJ}$ of the $532 \mathrm{~nm}$ output of a Neodymium-Yttrium-Aluminum-Garnet (Nd:YAG) laser were loosely focused at a repetition rate of $50 \mathrm{~Hz}$ to a $1 \mathrm{~mm}$ spot onto either a rotating graphite ( $99.995 \%$, Aldrich) or silicon ( $99.9999 \%$; ESPI) rod. The ablated species were then entrained in argon-seeded benzene $\left(\mathrm{C}_{6} \mathrm{H}_{6} ; 99.98 \%\right.$; OmniSolv $)$ at seeding fractions of about $11 \%$ or in neat acetylene gas $\left(\mathrm{C}_{2} \mathrm{H}_{2} ; 99.6 \%\right.$; Airgas), respectively; acetone traces in the acetylene gas were removed prior to introducing the acetylene inside the pulsed valve. The carrier gases, which also acted as reagents to form the polyynes in situ, were released by a Proch-Trickl pulsed valve operating at stagnation pressures of $1.2 \mathrm{~atm}$ and $1.5 \mathrm{~atm}$, respectively at a repetition rate of $50 \mathrm{~Hz}$. In a third experiment, we introduced argon-seeded diacetylene $\left(\mathrm{C}_{4} \mathrm{H}_{2}\right)$ gas at seeding fractions of $5 \%$ and backing pressures of $1.1 \mathrm{~atm}$ directly via the pulsed valve into the chamber. The goal of this control experiment was to compare the photoionization efficiency (PIE) curves obtained from the supersonic, argon-seeded diacetylene beam with those data extracted from in situ formed diacetylene in the laser ablation setup. Note that laser ablation sources could generate molecules which are ineffectively cooled in the supersonic beam (internally 'hot' molecules 
(Belau et al. 2007, Nicolas et al. 2006); the internal energy (particularly electronically excited states which can be metastable) of these species could result in a shift of the PIE curve to lower energies; this would yield lower onsets of the ion counts and hence lower ionization energies compared to the internally 'cold' molecules. Therefore, a comparison of the ionization energies of argon-seeded diacetylene with in situ generated diacetylene formed in the ablation processes helps to determine the degree of internal excitation; in an ideal case (no internal excitation), the ionization energies of diacetylene extracted from these three experiments should be identical. For the control experiment, diacetylene was synthesized according to the literature (Jones 1952; Zhou et al. 2009). Briefly, $9 \mathrm{~g}$ of 1,4-dichloro-2-butyne $\left(\mathrm{ClCH}_{2} \mathrm{CCCH}_{2} \mathrm{Cl}\right)$ were dissolved in 15 $\mathrm{ml}$ ethyl alcohol $\left(\mathrm{C}_{2} \mathrm{H}_{5} \mathrm{OH}\right)$ and warmed up to $353 \mathrm{~K}$. $60 \%$ aqueous sodium hydroxide $(\mathrm{NaOH})$ solution was added drop wise while stirring. White diacetylene vapor evolved and was carried away in a stream of helium carrier gas. The diacetylene gas was bubbled through a $13 \%$ aqueous sodium hydroxide solution, dried over calcium chloride, and frozen in a liquid nitrogen trap (77 K). Gas mixtures of $5 \%$ diacetylene in argon (99.9999\%; Gaspro) were prepared at $293 \mathrm{~K}$ and at a pressure of $3 \mathrm{~atm}$. These mixtures were stable for months. The purity of the diacetylene was checked via mass spectrometry and was found to be $99.5 \%+$ ).

Tunable VUV light from the Advanced Light Source crossed the neutral molecular beam 120 $\mathrm{mm}$ downstream of the ablation center and $65 \mathrm{~mm}$ after the skimmer in the extraction region of a Wiley-McLaren time-of-flight (TOF) mass spectrometer. The ions of the photoionized molecules were extracted and collected by a microchannel plate detector in the TOF mode utilizing a multi channel scaler. The photoionization efficiency (PIE) curves can be obtained by plotting the integrated counts of the ionized polyynes from diacetylene to nonaacetylene $\left(\left(\mathrm{H}-(\mathrm{C} \equiv \mathrm{C})_{\mathrm{n}}-\mathrm{H}^{+}\right)\right.$at mass-to-charges, $\mathrm{m} / \mathrm{z}$, of $\mathrm{m} / \mathrm{z}=(2+24 \times \mathrm{n})$ with $\mathrm{n}=2-9)$ versus the photoionization energy between $8.0 \mathrm{eV}$ and $10.5 \mathrm{eV}$ in steps of $0.05 \mathrm{eV}$. The signal was normalized to the photon flux. 
These PIE curves can be exploited to extract the adiabatic ionization energies of the polyynes.

\section{THEORETICAL}

The vertical and adiabatic ionization energies of polyynes, $\mathrm{H}-(\mathrm{C} \equiv \mathrm{C})_{\mathrm{n}}-\mathrm{H}(\mathrm{n}=1-9)$, were investigated with $a b$ initio electronic structure calculations. The optimized geometries and harmonic frequencies of the linear isomers for neutral and ionic polyynes were obtained at the level of the hybrid density functional theory, B3LYP/cc-pVTZ. After that, single-point CCSD(T)/ cc-pVDZ and $\operatorname{CCSD}(\mathrm{T}) / \mathrm{cc}-\mathrm{pVTZ}$ energies were computed. The $\operatorname{CCSD}(\mathrm{T})$ total energies were then extrapolated to the complete basis set limit $(\mathrm{CBS})$ using the formula $\mathrm{E}_{\text {total }}(\mathrm{CBS})=$ $\left(\mathrm{E}_{\text {total }}(\mathrm{VTZ})-\mathrm{E}_{\text {total }}(\mathrm{VDZ}) \times 2.5^{3} / 3.5^{3}\right) /\left(1-2.5^{3} / 3.5^{3}\right)$ (Huh \& Lee 2003). The adiabatic ionization energy of each polyyne was estimated by taking the energy difference between the respective ionic and neutral counterparts with zero-point energy corrections computed at the B3LYP/cc-pVTZ level included. The GAUSSIAN 03 program (Frisch et al. 2004) was employed for the B3LYP calculations, whereas spin-restricted $(\mathrm{R}) \operatorname{CCSD}(\mathrm{T})$ calculations were performed using the MOLPRO package (Werner et al. 2008).

\section{RESULTS \& DISCUSSION}

Our computations at the CCSD(T)/cc-pVTZ level with B3LYP/cc-pVTZ zero-point energy correction suggest that the adiabatic ionization energies decrease monotonically as the chain length increases from acetylene to nonaacetylene, i.e. from $11.26 \mathrm{eV}$ to $8.09 \mathrm{eV}$ (Table 1, Figure 1). This trend is also obtained at the B3LYP/cc-pVTZ level of theory with zero-point energy correction, which shows a decline from $11.23 \mathrm{eV}$ to $7.42 \mathrm{eV}$. For all polyacetylenes, ionization energies calculated at the B3LYP/cc-pVTZ level of theory are systematically lower compared to data obtained at the CCSD(T)/cc-pVTZ level of theory. The difference of the ionization energies increases steadily from initially $0.23 \mathrm{eV}$ for diacetylene up to $0.67 \mathrm{eV}$ for nonaacetylene. This

trend is also visualized in Figure 1. It is important to stress that the energies given in Table 2 
refer to the adiabatic ionization energy, i.e. the minimum energy required to photoionize a neutral molecule in its lowest rotational and vibrational ground state to create an ion in its lowest rotational and vibrational ground state (equation (3)). However, the geometry of a molecular ion can be very different from the neutral molecule. In this case, the experimentally measured ionization energy is the vertical ionization energy (equation (4)), and the value of the vibrational quantum number $v^{\prime}$ of the ion corresponds to the vibrational level whose wave function holds the largest overlap with the $v=0$ wave function. This presents the most probable transition with highest Franck Condon factors. In case of the polyynes, the geometries of the neutrals and the corresponding ions are very similar (Figure 2) so that the vertical ionization energies are expected to be very close to the adiabatic ionization energies. Our computations confirm this prediction yielding vertical ionization energies which are systematically higher than the adiabatic ionization energies by only $0.04-0.05 \mathrm{eV}$.

$$
\begin{aligned}
& M(v=0, j=0)+h v \rightarrow M^{+}\left(v^{\prime}=0, j^{\prime}=0\right)+e^{-} \\
& M(v=0, j=0)+h v \rightarrow M^{+}\left(v^{\prime}=n, j^{\prime}=m\right)+e^{-}
\end{aligned}
$$

Having discussed the theoretical ionization energies, we compare these data now with the experimental results (Figure 3; Table 1). As discussed in the experimental section, it is important to determine the degree of internal energy (vibrational, rotational) of the polyynes formed in the ablation processes. The PIE curve of argon-seeded diacetylene $(\mathrm{m} / \mathrm{z}=50)$ obtained from the control experiment shows an onset of $10.03 \mathrm{eV}$. This data is in excellent agreement with the adiabatic ionization energy from the NIST database $(10.0 \mathrm{eV})$ and also from our computations at the CCSD(T)/cc-pVTZ level of theory. The PIE curves of diacetylene generated in both laser ablation experiments have onsets of $10.0 \mathrm{eV}$ and $10.05 \mathrm{eV}$. These data are again in excellent agreement with the onset derived from the PIE of $\mathrm{m} / \mathrm{z}=50$ of diacetylene from the control experiment. Therefore, we can conclude that the polyacetylenes formed in the laser ablation 
experiments should have a negligible amount of internal energy and hence efficient cooling in the supersonic expansion. Let us turn our attention now to higher polyynes. In the silicon acetylene experiment, we also observed signal at $\mathrm{m} / \mathrm{z}=74$ and 98 , which can be attributed to $\mathrm{C}_{6} \mathrm{H}_{2}{ }^{+}$and $\mathrm{C}_{8} \mathrm{H}_{2}{ }^{+}$, respectively. As a matter of fact, the PIE curves show a perfect overlap with the PIE curves as derived from the carbon - benzene experiment. In both cases, onsets of the PIE curves were observed at $9.45 \mathrm{eV}$ and $9.05-9.10 \mathrm{eV}$ for $\mathrm{C}_{6} \mathrm{H}_{2}{ }^{+}$and $\mathrm{C}_{8} \mathrm{H}_{2}{ }^{+}$, respectively. A comparison of these data with the computed adiabatic ionization energies of 9.41 and $8.98 \mathrm{eV}$ for triacetylene and tetraacetylene shows a superb correlation between the computed and experimentally derived ionization energies. These data are also close to those of the NIST database of 9.50 and $9.09 \mathrm{eV}$, respectively.

The NIST database has no entries for polyynes higher than tetraacetylene. Moving on to the higher polyynes, in the carbon - benzene experiments signal at $\mathrm{m} / \mathrm{z}=122,146,170,194$, and 218, is assigned to $\mathrm{C}_{10} \mathrm{H}_{2}{ }^{+}, \mathrm{C}_{12} \mathrm{H}_{2}{ }^{+}, \mathrm{C}_{14} \mathrm{H}_{2}{ }^{+}, \mathrm{C}_{16} \mathrm{H}_{2}{ }^{+}$, and $\mathrm{C}_{18} \mathrm{H}_{2}{ }^{+}$. The corresponding PIE curves are shown in Figure 3 with onsets extracted at $8.75 \mathrm{eV}, 8.65 \mathrm{eV}$, and $8.50 \mathrm{eV}$ for pentaacetylene to heptaacetylene. A comparison with the computed energies in Table 1 does suggest the presence of penta-, hexa-, and heptaacetylene in the supersonic beam. Figure 3 visualizes the agreement between the theoretically and experimentally determined ionization energies of the polyacetylenes up to around heptaacetylene $\left(\mathrm{C}_{14} \mathrm{H}_{2}\right)$. Octaacetylene $\left(\mathrm{C}_{16} \mathrm{H}_{2}\right)$ and nonaacetylene $\left(\mathrm{C}_{18} \mathrm{H}_{2}\right)$ show increased deviations between the calculated and experimental ionization energies. This can be seen by a comparison of the calculated data (as indicated by arrows) and the rise of the PIE curve. This could either arise from different isomers being populated in the molecular beam for these long chain species or from the limited signal-to-noise obtained for these higher polyynes. Also, for those higher polyynes, the cation could be unstable and dissociative photoionization might explain the absence of signal at the calculated onsets. It would be fruitful to 
have future calculations performed to elucidate the energetics of photodissociation and photoionization processes.

\section{ASTROPHYSICAL IMPLICATIONS}

The postulation of polyacetylenes as important building blocks to form polycyclic aromatic hydrocarbons (PAHs) (Pardo \& Cernicharo 2007) in the proto planetary nebulae CRL 618 (Cernicharo et al. 2001) requires accurate input parameters of astrochemical models simulating the chemistry. The central star emits an intense photon field; therefore, molecules can not only be photodissociated, but they are also photoionized. The radicals and molecular ions formed in the photodissociation and ionization processes can undergo subsequent radical and also ion- molecule reactions. Our combined experimental and theoretical investigation provided a set of crucial astrophysical data, which can be included with significant confidence in astrochemical models of photon-dominated regions and also to the circumstellar envelope of the proto planetary nebulae CRL 618. These are accurate ionization energies of poly acetylenes from diacetylene up to heptaacetylene. Based on our study, we would like to recommend the following ionization energies with an experimental accuracy of $\pm 0.05 \mathrm{eV}: 10.03 \mathrm{eV}$ (diacetylene), $9.45 \mathrm{eV}$ (triacetylene), 9.08 $\mathrm{eV}$ (tetraacetylene), $8.75 \mathrm{eV}$ (pentaacetylene), $8.65 \mathrm{eV}$ (hexaacetylene), and $8.50 \mathrm{eV}$ (heptaacetylene); the ionization energies of octaacetylene $(8.32 \mathrm{eV})$ and of nonacetylene $(8.24 \mathrm{eV})$ were calculated within an accuracy of $\pm 0.1 \mathrm{eV}$.

These studies have also implications to the chemistry of hydrocarbon-rich atmospheres of planets and their moons. Considering Titan as a model case, Titan's atmospheric composition is altered by an external influx of matter as supplied by (micro)meteorites and possibly comets (Horst et al.2008). The impact of (micro)meteorites with dense atmospheres also leads to an ablation of the meteoritic material releasing ground and excited metal atoms (mostly iron (Fe), magnesium (Mg), and silicon (Si) from abundant silicates) and multiply charged ions (Petrie 
2001; Petrie \& Dunbar 2006). For instance, the first and second ionization energies of magnesium, silicon, and iron were determined to be 7.64 and $15.00 \mathrm{eV}(\mathrm{Mg}), 8.15$ and $16.34 \mathrm{eV}(\mathrm{Si})$, and 7.86 and $16.18 \mathrm{eV}(\mathrm{Fe})$, respectively. A comparison with the ionization energies of the polyynes suggests that singly charged iron, magnesium, and silicon ions cannot ionize any polyacetylenes upon collision. However, the second ionization energies of iron, magnesium, and silicon are well above the ionization energies of any polyyne investigated. Therefore, upon collision, charge-transfer processes between the doubly ionized atoms and the neutral polyyne can lead to the formation of only a singly charged magnesium, silicon, and iron ion plus an ionized polyacetylene species. An investigation of these metal-ion mediated redox reactions in the upper atmospheres of hydrocarbon rich planets and their moons are in their infancy. Since the singly ionized polyacetylenes can undergo further ion-molecule reactions, the charge-exchange reactions are expected to have a profound effect on the overall hydrocarbon balance in hydrocarbon-rich atmospheres.

\section{ACKNOWLEDGEMENTS}

RIK and AMM thank the Chemistry Division of the US National Science Foundation for support within the framework of the Collaborative Research in Chemistry (CRC) Program (NSF-CRC CHE-0627854). MA and OK gratefully acknowledge support from the Director, Office of Energy Research, Office of Basic Energy Sciences, Chemical Sciences Division of the U.S. Department of Energy under contract No. DE-AC02-05CH11231. BJS, HML, and AHHC thank the National Center for High-performance Computer of Taiwan for the computer resources utilized in the calculations. 


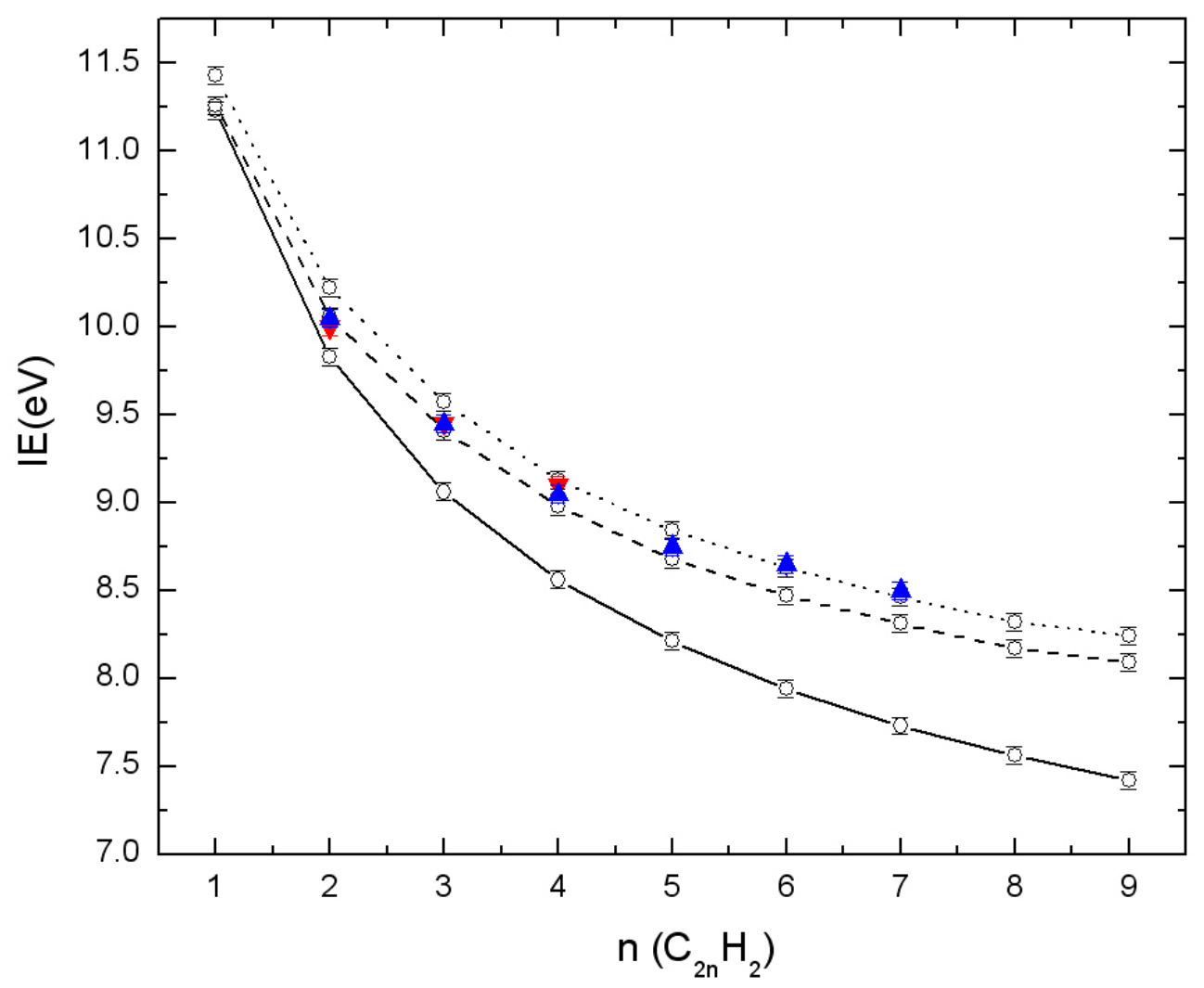

Figure 1. Computed and experimental ionization energies for distinct polyynes $\left(\left(\mathrm{H}-(\mathrm{C} \equiv \mathrm{C})_{\mathrm{n}}-\mathrm{H}\right)\right.$ from diacetylene $(\mathrm{n}=2)$ to nonaacetylene $(\mathrm{n}=9)$. Black solid line: B3LYP/cc-pVTZ with zero-point energy correction; black dashed line: $\operatorname{CCSD}(\mathrm{T}) / \mathrm{cc}-\mathrm{pVTZ}$ with $\mathrm{B} 3 \mathrm{LYP} / \mathrm{cc}-\mathrm{pVTZ}$ zero-point energy correction; black dotted line: CCSD(T)/CBS with B3LYP/cc-pVTZ zero-point energy correction; red triangles: experimental data silicon/acetylene experiment; blue triangles: carbon/ benzene experiment. 


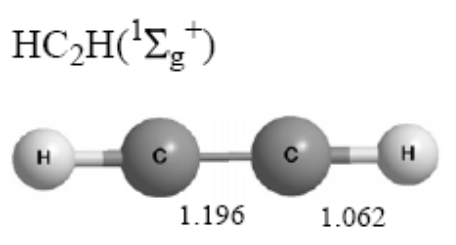

$\mathrm{HC}_{4} \mathrm{H}\left({ }^{1} \Sigma_{\mathrm{g}}{ }^{+}\right)$

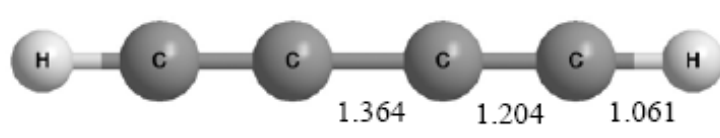

$\mathrm{HC}_{2} \mathrm{H}^{+}\left({ }^{2} \Pi_{\mathrm{u}}\right)$

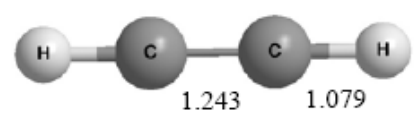

$\mathrm{HC}_{4} \mathrm{H}^{+}\left({ }^{2} \Pi_{\mathrm{g}}\right)$

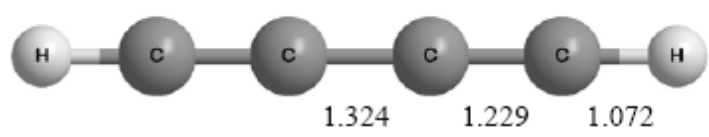

$\mathrm{HC}_{6} \mathrm{H}\left({ }^{1} \Sigma_{\mathrm{g}}{ }^{+}\right)$

$\mathrm{HC}_{6} \mathrm{H}^{+}\left({ }^{2} \Pi_{\mathfrak{u}}\right)$

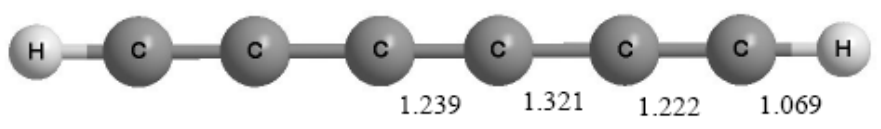

$\mathrm{HC}_{8} \mathrm{H}\left({ }^{1} \Sigma_{\mathrm{g}}{ }^{+}\right)$

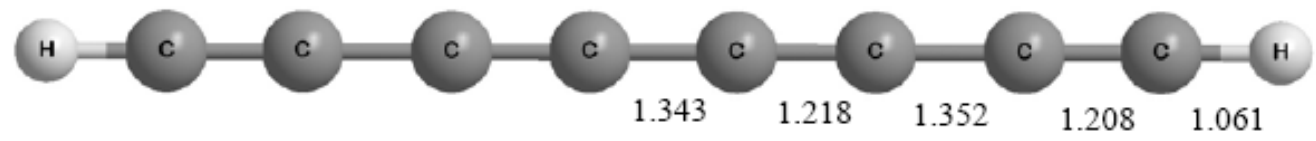

$\mathrm{HC}_{8} \mathrm{H}^{+}\left({ }^{2} \Pi_{\mathrm{g}}\right)$

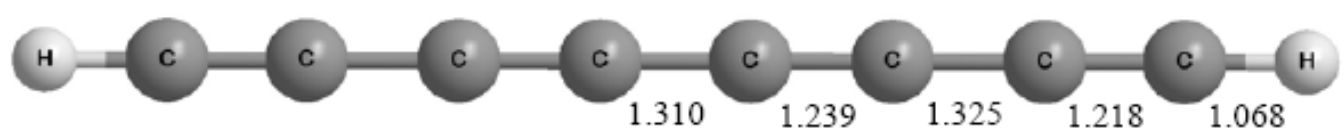




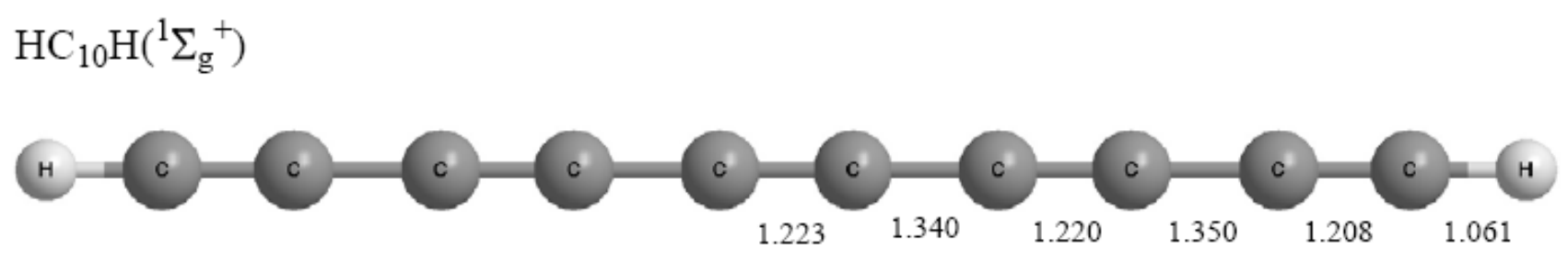

$\mathrm{HC}_{10} \mathrm{H}^{+}\left({ }^{2} \Pi_{\mathrm{v}}\right)$

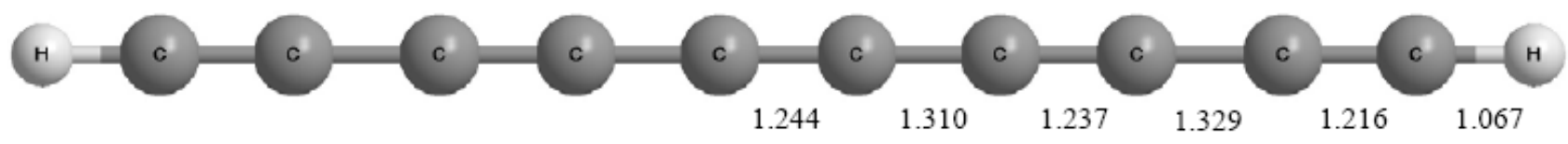

$\mathrm{HC}_{12} \mathrm{H}\left({ }^{1} \Sigma_{\mathrm{g}}{ }^{+}\right)$
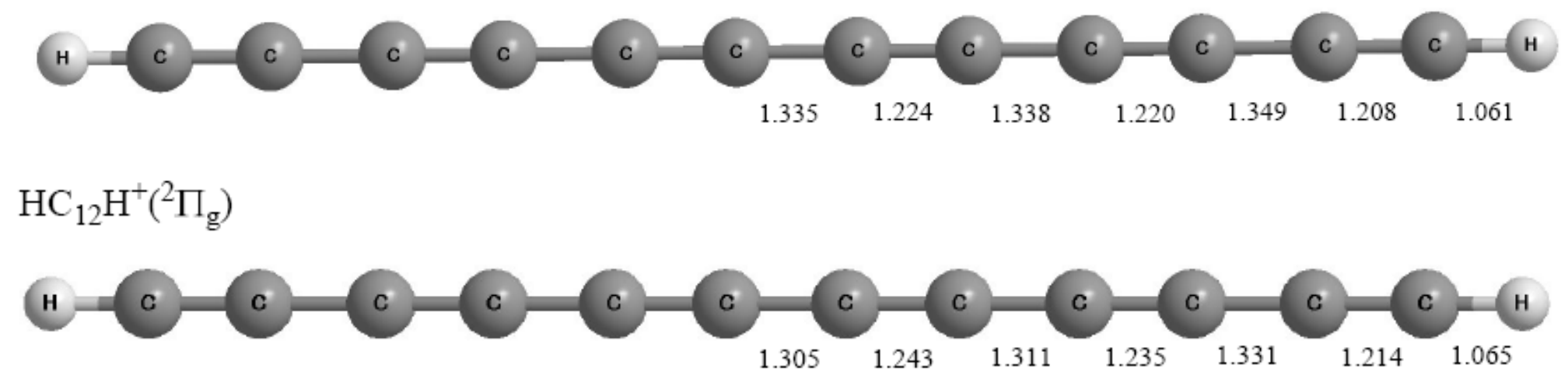

$\mathrm{HC}_{14} \mathrm{H}\left({ }^{1} \Sigma_{\mathrm{g}}{ }^{+}\right)$

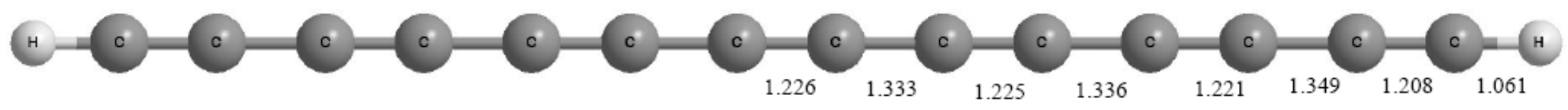



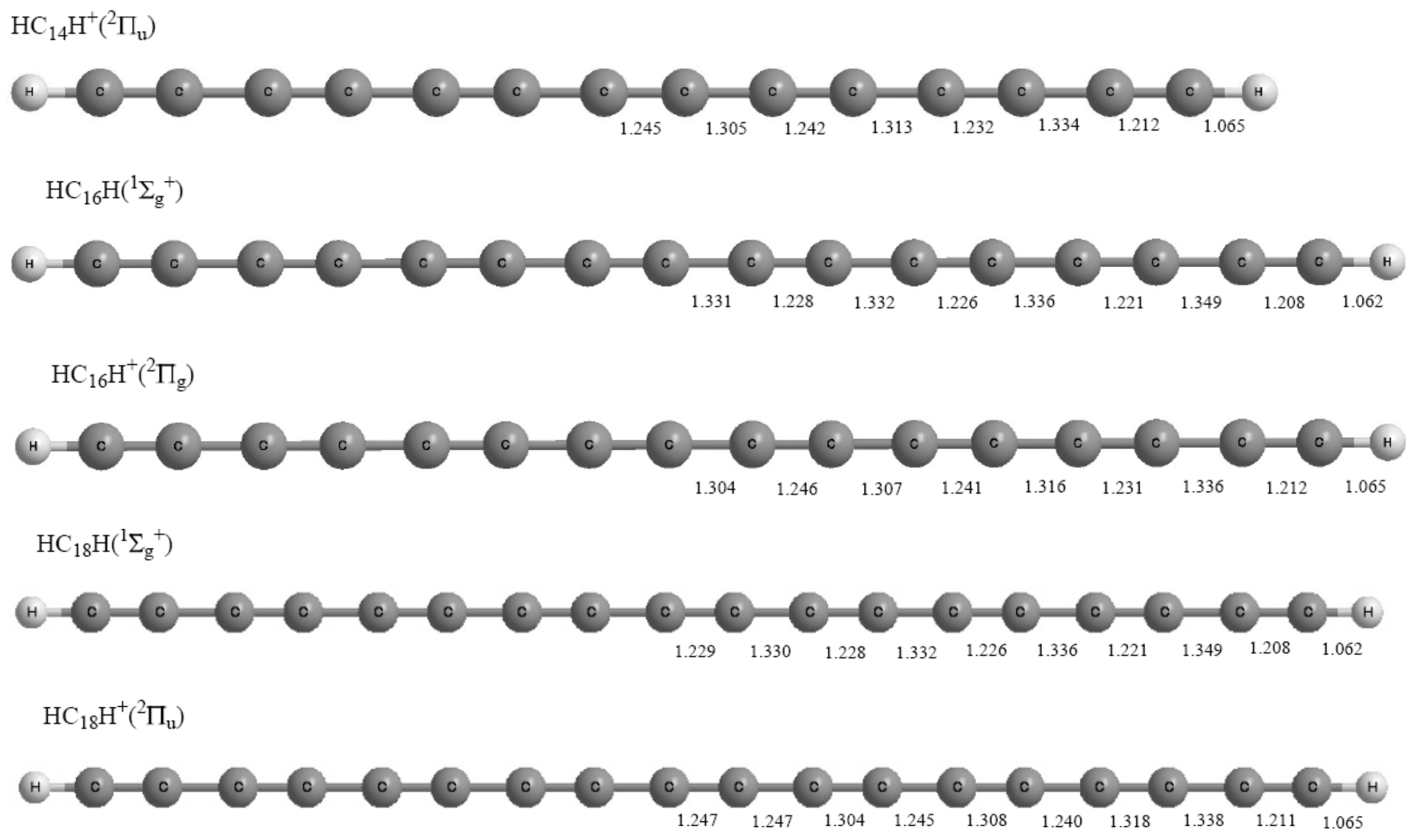

Figure 2. Geometries of neutral and ionic polyynes optimized at the B3LYP/cc-pVTZ level of theory. Bond lengths are given in Angstrom. Electronic states are also shown. All neutral and singly ionized polyynes belong to the $\mathrm{D}_{\infty \mathrm{h}}$ point group. 

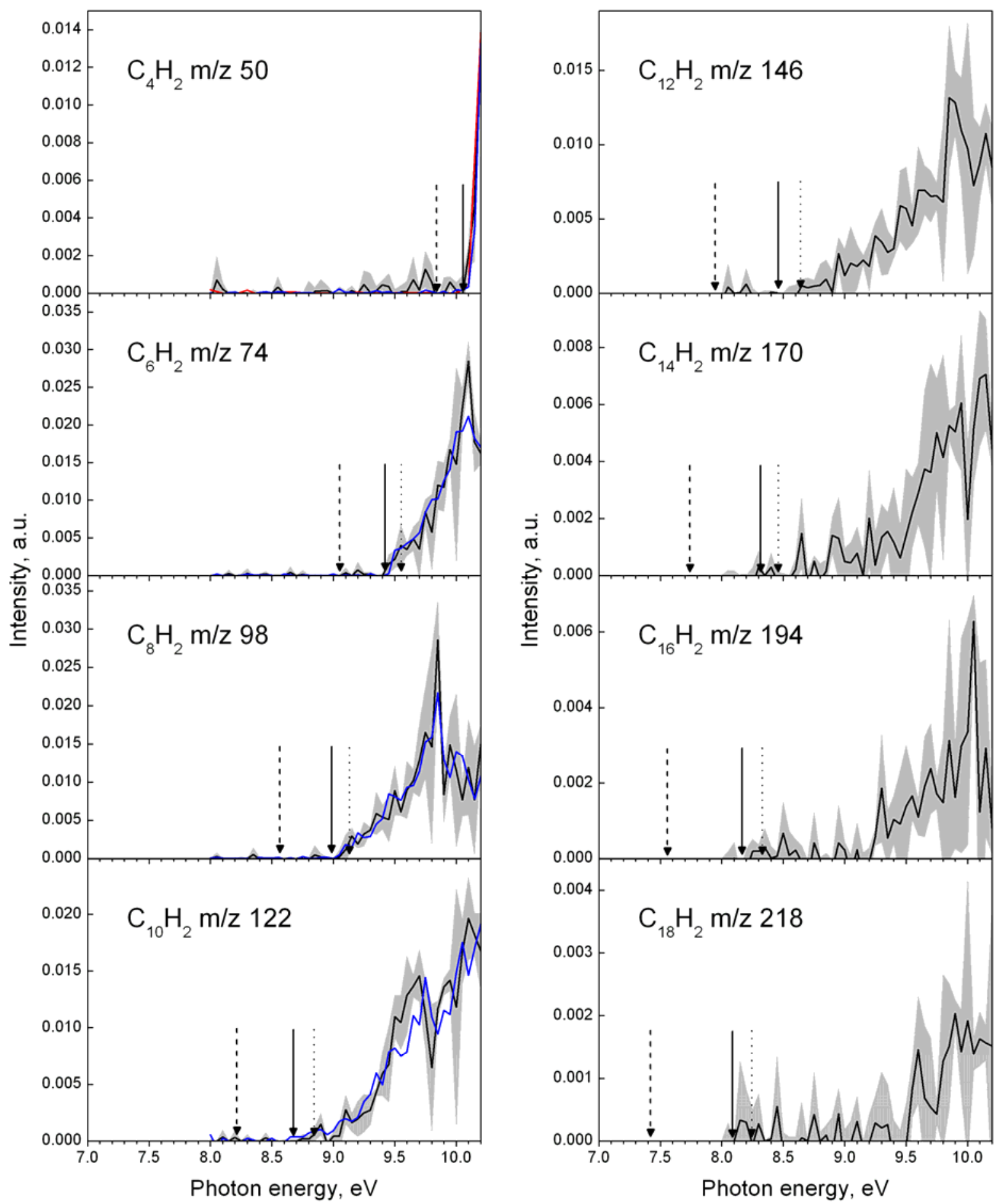

Figure 3. Photoionization efficiency curves (PIE) for ions of $\mathrm{C}_{2 n} \mathrm{H}_{2}(\mathrm{n}=2-9)$. Black solid lines correspond to PIE curves measured for the carbon ablation experiment with benzene; gray area represents standard deviation. Blue lines represent PIE curves recorded in the silicon experiment with acetylene gas. The red line corresponds to PIE for argon-seeded diacetylene. The arrows (dashed: B3LYP/cc-pVTZ, solid: CCSD(T)/cc-pVTZ, dotted: CCSD(T)/CBS) represent positions of theoretically calculated adiabatic ionization energies as compiled in Table 1. 
Table 1: Adiabatic ionization energies of various polyynes. ${ }^{a}$ Ionization energies by B3LYP/cc-pVTZ with zero-point energy correction. ${ }^{\mathrm{b}}$ Ionization energies by $\operatorname{CCSD}(\mathrm{T}) / \mathrm{cc}-\mathrm{pVTZ}$ with B3LYP/cc-pVTZ zero-point energy correction. ${ }^{\mathrm{c}}$ Ionization energies by $\operatorname{CCSD}(\mathrm{T}) / \mathrm{CBS}$ with CBS extrapolation using $\mathrm{E}_{\text {total }}(\mathrm{CBS})=\left(\mathrm{E}_{\text {total }}(\mathrm{VTZ})-\mathrm{E}_{\text {total }}(\mathrm{VDZ}) \times 2.5^{3} / 3.5^{3}\right) /\left(1-2.5^{3} / 3.5^{3}\right)($ Huh \& Lee 2003), with B3LYP/cc-pVTZ zero-point energy correction. ${ }^{\mathrm{d}}$ Silicon/acetylene experiment. ${ }^{\mathrm{e}}$ Carbon/benzene experiment. ${ }^{\mathrm{f}}$ Control experiment ${ }^{\mathrm{g}}$ See text for discussion.

\begin{tabular}{lcccccc}
\hline & $\mathrm{IP}(\mathrm{eV})^{\mathrm{a}}$ & $\mathrm{IP}(\mathrm{eV})^{\mathrm{b}}$ & $\mathrm{IP}(\mathrm{eV})^{\mathrm{c}}$ & $\mathrm{IP}(\mathrm{eV})^{\mathrm{d}}$ & $\mathrm{IP}(\mathrm{eV})^{\mathrm{e}}$ & $\mathrm{IP}(\mathrm{eV})^{\mathrm{f}}$ \\
$\mathrm{HC}{ }_{2} \mathrm{H}\left({ }^{1} \Sigma_{\mathrm{g}}^{+} \rightarrow{ }^{2} \Pi_{\mathrm{u}}\right)$ & 11.23 & 11.26 & 11.43 & & & \\
$\mathrm{HC}{ }_{4} \mathrm{H}\left({ }^{1} \Sigma_{\mathrm{g}}{ }^{+}{ }^{2} \Pi_{\mathrm{g}}\right)$ & 9.83 & 10.06 & 10.22 & 10.00 & 10.05 & 10.03 \\
$\mathrm{HC}_{6} \mathrm{H}\left({ }^{1} \Sigma_{\mathrm{g}}{ }^{+} \rightarrow{ }^{2} \Pi_{\mathrm{u}}\right)$ & 9.06 & 9.41 & 9.57 & 9.45 & 9.45 & - \\
$\mathrm{HC}_{8} \mathrm{H}\left({ }^{1} \Sigma_{\mathrm{g}} \rightarrow^{2} \Pi_{\mathrm{g}}\right)$ & 8.56 & 8.98 & 9.13 & 9.10 & 9.05 & - \\
$\mathrm{HC}_{10} \mathrm{H}\left({ }^{1} \Sigma_{\mathrm{g}}^{+} \rightarrow{ }^{2} \Pi_{\mathrm{u}}\right)$ & 8.21 & 8.68 & 8.84 & - & 8.75 & - \\
$\mathrm{HC}_{12} \mathrm{H}\left({ }^{1} \Sigma_{\mathrm{g}}^{+} \rightarrow{ }^{2} \Pi_{\mathrm{g}}\right)$ & 7.94 & 8.47 & 8.63 & - & 8.65 & - \\
$\mathrm{HC}_{14} \mathrm{H}\left({ }^{1} \Sigma_{\mathrm{g}}^{+} \rightarrow{ }^{2} \Pi_{\mathrm{u}}\right)$ & 7.73 & 8.31 & 8.46 & - & 8.50 & - \\
$\mathrm{HC}_{16} \mathrm{H}\left({ }^{1} \Sigma_{\mathrm{g}} \rightarrow^{2} \Pi_{\mathrm{g}}\right)$ & 7.56 & 8.17 & 8.32 & - & $\mathrm{g}$ & - \\
$\mathrm{HC}_{18} \mathrm{H}\left({ }^{1} \Sigma_{\mathrm{g}}^{+} \rightarrow{ }^{2} \Pi_{\mathrm{u}}\right)$ & 7.42 & 8.09 & 8.24 & - & $\mathrm{g}$ & - \\
\hline
\end{tabular}


Belau, L., Wheeler, S. E., Ticknor, B. W., Ahmed, M., Leone, S. R., Allen, W. D., Schaefer, H. F., Duncan, M. A., 2007, JACS, 129, 10229.

Boechat-Roberty, H. M., Neves, R., Pilling, S., Lago, A. F., de Souza, G. G. B., 2009, Monthly Notices of the Royal Astronomical Society, 394, 810.

Cernicharo, J. et al., 2001, Astrophysical Journal Lett. (2001), 546, L123.

Cernicharo, J. 2004, Astrophysical Journal Lett., 608, L41.

Cordiner, M. A., Millar, T. J., 2009, Astrophysical Journal, 697, 68.

Duley, W. W., Grishko, V. I., Kenel, J., Lee-Dadswell, G., Scott, A., 2005, Astrophysical Journal, $626,933$.

Frisch, M. J., et al. 2004, GAUSSIAN 03 (Wallingford CT: Gaussian, Inc.)

Gu, X., Kim, Y.S., Kaiser, R.I., Mebel, A.M., Liang, M.C., Yung, M.C., 2009, Proceedings National Academy of Sciences, 106, 16078.

Hansen, N., Klippenstein, S. J., Westmoreland, P. R., Kasper, T., Kohse-Hoeinghaus, K., Wang, J., Cool, T. A. 2008, Physical Chemistry Chemical Physics, 10, 366.

Heimann, A., Koike, M., Hsu, C.W., Blank, D., Yang, X.M., Suits, A.G., Lee, Y. T., Evans, M., $\mathrm{Ng}$

C.Y., Flaim, C., Padmore, H.A. 1997, Rev. Sci. Instrum., 68, 1945.

Horst, S.M., Vuitton 2008, J. Geophys. Res. [Planets] 113, E10006.

Huh, S.B., Lee, J.S. 2003, J. Chem. Phys., 118, 3035.

Jones, A. V., 1952. Infrared and Raman spectra of biacetylene. Proc. R. Soc. London, Ser. A. 211, 285.

Kaiser, R.I., Belau, L., Leone, S.R., Ahmed, Wang, Y., Braams, B.J., Bowman, J.M., 2007, Chem Phys Chem 8, 1236.

Li, Y., Zhang, L., Tian, Z., Yuan, T., Zhang, K., Yang, B., Qi, F., 2009, Proceedings of the 
Combustion Institute, 32, 1293.

Nicolas, C., Shu, J.N., Peterka, D.S., Hochlaf, M., Poisson, L., Leone, S.R., Ahmed, M. 2006, J.

Am. Chem. Soc., 128, 220.

Pardo, J.R., Cernicharo, J., 2007, Astrophysical Journal, 654, 978.

Petrie, S., 2004, Icarus, 171, 199.

Petrie, S., Dunbar, R.C., 2006, AIP Conf. Proc. Astrochemistry, 855, 272.

Werner, H.-J., et al. 2006, MOLPRO, version 2006.1, A package of ab initio programs, http://www.molpro.net

Woods, P.M., Millar, T. J., Zijlstra, A.A., Herbst, E., 2003 (Planetary Nebulae: Their Evolution and Role in the Universe), 279-280.

Woods, P.M., Millar, T. J., Zulstra, A.A., Herbst, E., 2002, Astrophysical Journal Lett. , 2002, 574, L167.

Zhou, L., Kaiser, R.I., Tokunaga, A.T., 2009, Planet. Space Sciences 57, 830. 